\title{
Transformative learning to promote sustainability: inserting the third level of learning in management programs
}

\author{
Lisiane Celia Palma ${ }^{*}$ and Eugênio Ávila Pedrozo ${ }^{2}$
}

*Correspondence:
lisianepalma@yahoo.com.br
${ }^{1}$ IFRS (Federal Institute
of Education, Science
and Technology of Rio
Grande do Sul), Canoas, Rio
Grande do Sul, Brazil
Full list of author information
is available at the end of the
article

*Correspondence: lisianepalma@yahoo.com.br f Education, Science and Technology of Rio Grande do Sul), Canoas, Rio Grande do Sul, Brazil is available at the end of the article

\begin{abstract}
Sustainability is a complex issue, which has required individual, organisational and social changes. Therefore, programs related to management play an important role, since they educate the majority of managers that lead organisations. They can therefore prepare them to lead organisations more committed to sustainability. To this end, some studies show that such programs need to go through a transformative learning process, both at the individual and organisational level. Thus, this article aims to present an expanded framework of the integrated model of organisational learning by inserting transformative learning as a proposal for the programs related to the field of management to increase their contributions to sustainability. It also presents a case study of a postgraduate program at an educational institution that seeks to promote transformative learning. The case study was developed for the application of the framework. The main contributions of this study highlight the importance of expanding individuals' mental models and shared mental models in organisations that take place, respectively, through critical reflection and the promotion of spaces where the mental models of different stakeholders can be shared.
\end{abstract}

Keywords: Transformative learning, Sustainability, Management programs, Stakeholders

\section{Background}

Sustainability is a complex issue, which has required changes in individuals, organisations and society as a whole. Therefore, the programs related to the management area have an important role, since they educate the majority of managers that lead organisations. Consequently, they can prepare these managers to lead organisations that are more committed to the environment and society.

Changes have been observed in these programs for the inclusion of issues related to sustainability (e.g.: Stubbs and Cocklin 2008; Palma et al. 2011; Demajorovic and Silva 2012). Yet, these are still incipient and often related to maintaining the status quo, without the intention of rebuilding or moving towards sustainable, interdisciplinary or transdisciplinary proposals. According to Carvalho et al. (2014), there is still a lack in the construction of the most robust educational actions, with regard to educating a new generation of managers prepared to meet the demands of a sustainable logic.

(C) 2016 Palma and Pedrozo. This article is distributed under the terms of the Creative Commons Attribution 4.0 International License (http://creativecommons.org/licenses/by/4.0/), which permits unrestricted use, distribution, and reproduction in any medium, provided you give appropriate credit to the original author(s) and the source, provide a link to the Creative Commons license, and indicate if changes were made. 
Barin-Cruz et al. (2006) argues that in order for organisations to move toward strategies aimed at sustainability, they must go through an evolutionary process moving from a financial-economic to a sustainable logic. Thus, Education Institutions (EIs) in general, and management programs specifically, need to go through a learning process to promote a transformation to sustainability. Considering that this transformation requires a paradigm shift (Batie 2008; Sterling 2010-2011), this process is related to transformative learning.

Transformative learning seeks to promote changes that go beyond behavioral change, posing a challenge to existing beliefs and ideas, and promoting the reconstruction of meanings. It suggests a more radical paradigm shift, rather than a change within the existing paradigm.

Thus, this article aims to present an expanded framework of the integrated organisational learning model proposed by $\operatorname{Kim}(1993,1998)$, in order to insert transformative learning in programs related to management. Moreover, it presents the application of this framework in a program related to the management area.

Therefore, it begins with a reflexion on sustainability and its different interpretations. Soon after, it introduces a discussion of organisational learning and its relation to individual learning, presenting Kim's (1993, 1998) model. Then, transformative learning is introduced, followed by the proposed framework. The method, main results and analysis, appear in "Methods" and "Results and discussion" sections, respectively. Finally, some conclusions of the study are highlighted.

\section{Sustainability and its different interpretations}

With the advent of the Industrial Revolution and later the so-called Fordist society, as well as the patterns of mass production and consumption it brought, environmental problems intensified and became increasingly more visible to the society. Since then, a series of events have occurred to raise awareness of the environmental problems that have begun to appear worldwide (Dias 2006; Barbieri 2007).

Of note was the establishment of the World Commission on Environment and Development by the UN in 1983. A report entitled "Our Common Future", also known as the "Brundtland Report", which was published by this commission in 1987, formalized the concept of Sustainable Development (SD) as meeting the needs of the present without compromising future generations from meeting their own needs. This action made the global necessity to adopt a new type of development evident. The document was an important reference and basis for the debates that occurred during the United Nations Conference on Environment and Development, the Earth Summit, held in Rio de Janeiro in 1992. At this event the concept of SD became popular and environmental and developmental issues became inextricably linked (Dias 2006).

However, the multiple interpretations of SD are confusing, and clearly sustainability has diverse meanings for different audiences. Authors discuss this question by presenting distinct interpretations and definitions for the subject (e.g. Gladwin et al. 1995; LealFilho 2000; Hopwood et al. 2005), as well as different possible strategies to reach it (e.g. Graaf et al. 1996; Veiga 2005). As stated by Leal-Filho (2000), it is improbable that a consensus about the meaning of sustainable development can be reached, because its own 
definition is influenced by the training, work experience, and political scenarios experienced by each person.

Over the years, even the pillars of sustainability (economic, social, and environmental) have been complemented and expanded. Steurer et al. (2005) developed a framework of reference for SD, "a kind of inventory which pinpoints what SD actually means on the microeconomic level" (Steurer et al. 2005, p. 269). They expand the triple bottom line by proposing a fourth dimension which comprises some issues that are of a general conceptual character, or are relevant for all three dimensions (economic, social and environmental) such as transparency and participation, reflectivity, integration and intergenerational equity/foresight.

In order to help make sense of the multiple interpretations of SD, Hopwood et al. (2005) suggest a mapping methodology based on the combination of environmental and socio-economic issues on two separate axes (Fig. 1). The socioeconomic axis covers the level of importance given to human well-being and equality. The environmental axis covers the environmental priority from technocentric to ecocentric. The shaded central area of the map indicates the range of opinions in the debate on the SD, combining socioeconomic and environmental issues. There are some points of view out of this area, concerned with only environmental or socio-economic issues.

Superimposed in Fig. 1 are three broad views about the nature of the necessary policy changes in society, in economic structures and relationships between man and the environment to achieve SD: (1) that can be achieved within the present structures-status quo; (2) that a fundamental reform is necessary, but without a complete rupture with the existing arrangements-reform; and (3) that, as the roots of the problems are their own economic structures and the power of society, a radical transformation is neededtransformation (Hopwood et al. 2005).

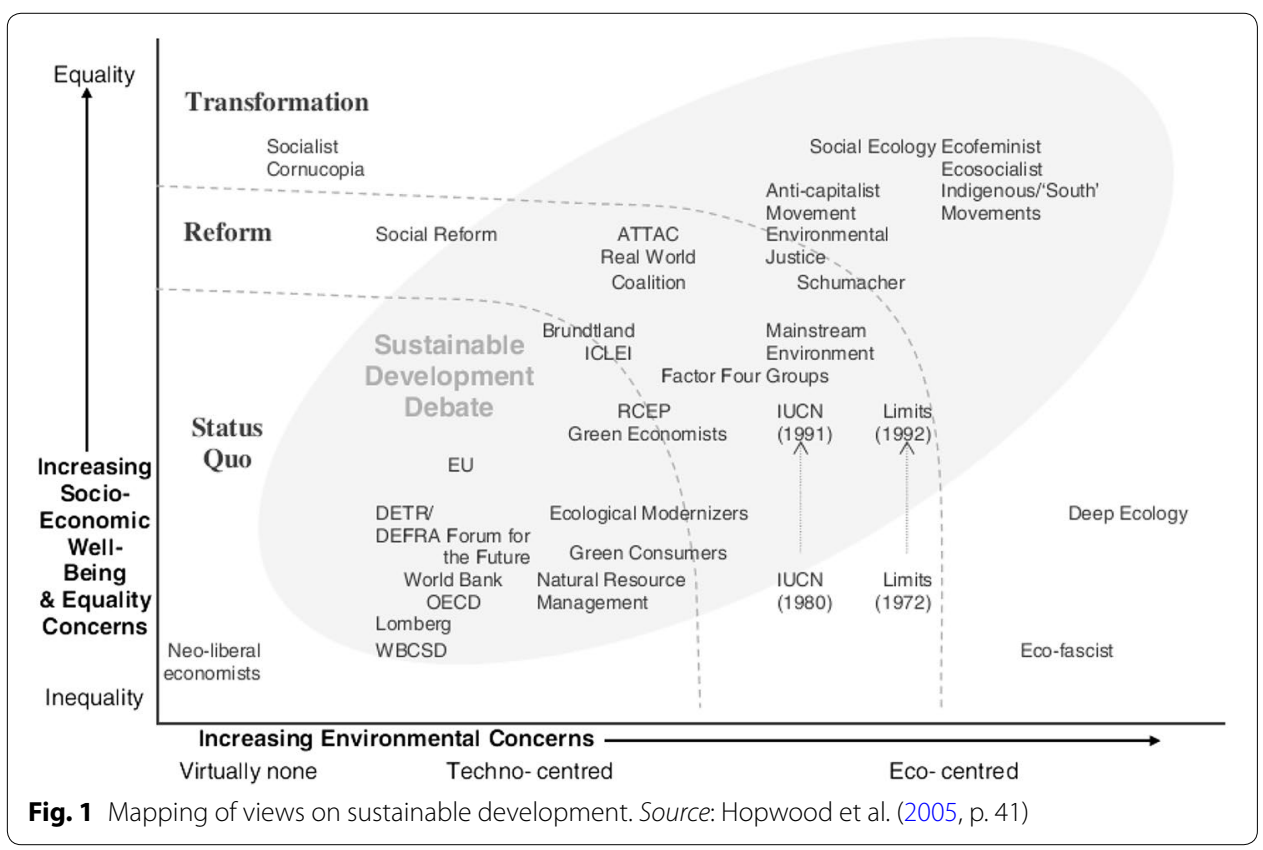


Thus, it is possible to state that sustainability beyond the status quo demands a transformation. However, the prevailing logic in programs for managers is based on the Neoclassical approach and Homo Economics. In this sense, sustainability, when addressed, is often analyzed only under one view-the mainstream.

However, if such programs are intended to contribute to sustainability by empowering managers to be agents of change, they must change. In fact, they must undergo a learning process, which is discussed below.

\section{Organisational learning process}

Since 1960, several authors have explored the subject of organisational learning (e.g.: Argyris 1964; March and Olsen 1975; Senge; 1990; Argyris and Shon 1996). However the literature in this field remains fragmented, consisting of many different definitions and concepts. As highlighted by Prange (2001, p. 42), "the multiplicity of ways in which organisational learning has been classified and used, has the sense of a "jungle of organisational learning, which is becoming increasingly dense and impenetrable."

According to Prange (2001), it remains unclear whether we are talking about individual learning in organisations, organisational learning equivalent to individual learning, or some kind of emerging or collective learning. Similarly, Kim $(1993,1998)$ emphasizes that

if a distinction between organisation and individual in not made explicit, a model of organisational learning will either obscure the actual learning process by ignoring the role of the individual (and anthropomorphizing organisations) or become a simplistic extension of individual learning by glossing over organisational complexities (Kim 1993, p. 9).

Thus, the model proposed by $\operatorname{Kim}(1993,1998)$ proves to be quite relevant to understand the process of organisational learning. The author builds a theory about the process through which individual learning advances organisational learning and presents a framework that focuses on the crucial link between these types of learning (Fig. 2). The author entitles this model OADI-SMM: observe, assess, design, implement-shared mental models.

Kim (1993, p. 2) initially posits that learning encompasses "what people learn (knowhow) and how they understand and apply this learning (know-why)." Learning, therefore, can be said to “increase one's capacity to take effective action” (Kim 1993, p. 3).

He uses the learning cycle (observe, assess, design, implement-OADI) as the basis of his individual learning model. This model is shown in the upper part of Fig. 2, which refers to individual learning. According to the author,

In the OADI cycle, people experience concrete events and actively observe what is happening. They access (consciously or unconsciously) their experiences by reflecting on their observations and then design or construct an abstract concept that seems to be an appropriate response to the assessment. They test the design by implementing it in the concrete world, which leads to a new concrete experience, commencing another cycle (Kim 1993, p. 3). 


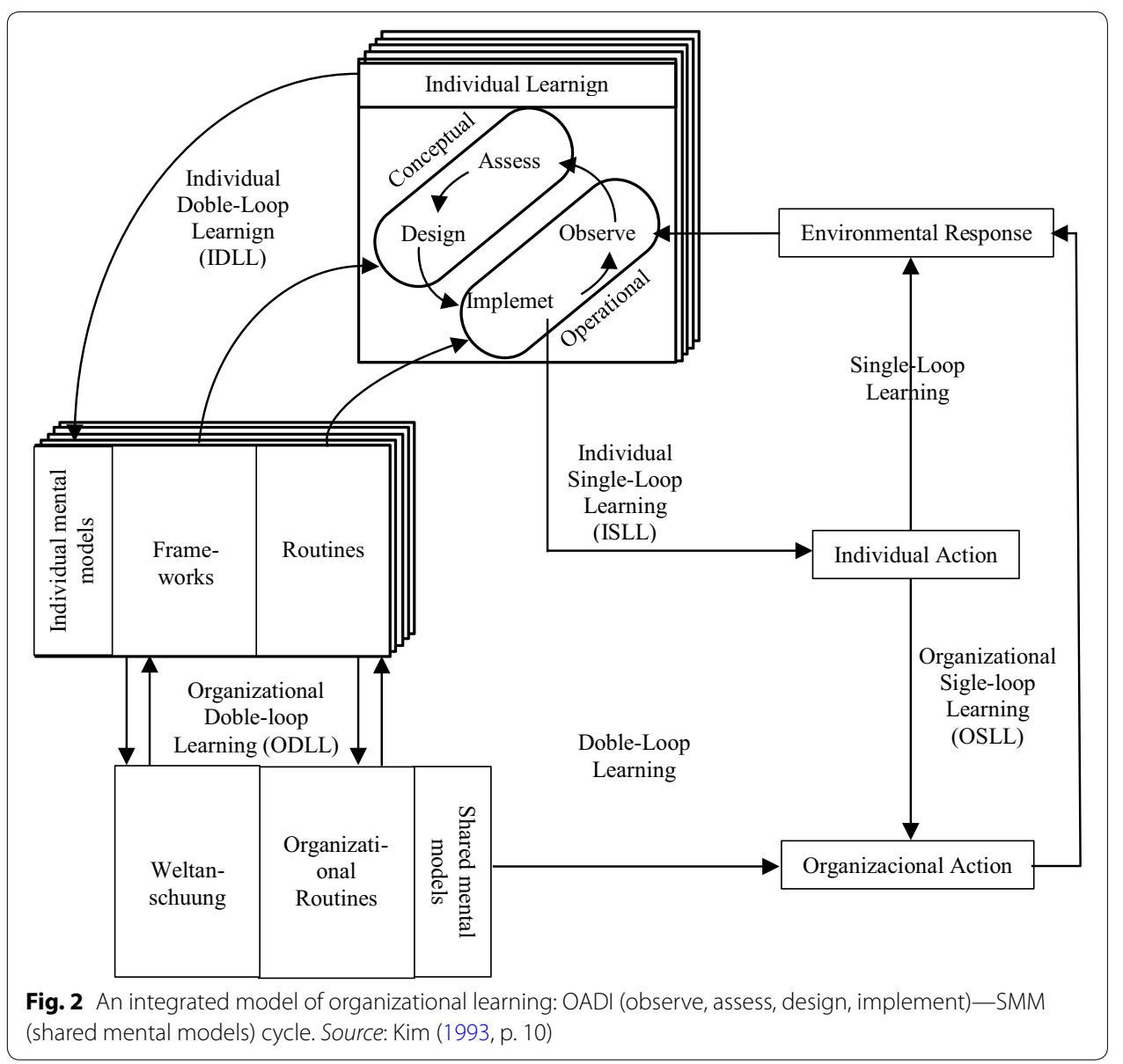

The author adds memory to the model, which has a key role in linking the organisational and individual learning. He stresses that it is important to distinguish between learning and memory. Learning has more to do with acquisition, while memory is related to the retention of whatever is acquired. To understand the role of memory in the learning process, it is important to understand the concept of a mental model, which "differs from the traditional notion of memory as static storage because mental models play an active role in what an individual sees and does" (Kim 1993, p. 4).

Mental models represent a person's view of the world, including explicit and implicit understandings. Mental models provide the context in which to view and interpret the new material, and they determine how stored information is relevant to a given situation. (...) Mental models not only help us to make sense of the world we see, they can also restrict our understanding to that which makes sense within the mental model (Kim 1993, p. 4).

The two levels of learning previously presented-operational and conceptual-can be related to the two parts of the mental model. Operational learning represents learning at the procedural level, when one learns the steps to complete a specific task. It can be understood as routines. Not only does operational learning accumulate and change routines, but routines also affect the operational learning process. On the other hand, 
conceptual learning is related to the reasoning about why things are done in the first place. It sometimes challenges even the nature or the existence of existing conditions, procedure or concepts and leads to new frameworks in the mental model. This, in turn, can create opportunities for discontinuous steps for improvement by reframing a problem in a radically different way (Kim 1993, 1998).

Kim $(1993,1998)$ highlights that organisational learning, in turn, is more complex and dynamic than mere amplification of individual learning. Similar to individual learning, organisational learning is defined as an increase of the organisation's ability to act effectively. In the model, the individual learning loop is a process by which beliefs change and these changes are then encoded into individual mental models. The individual learning cycle affects learning at the organisational level due to its influence on the shared mental models of the organisation. An organisation can only learn through its members, but that does not depend on any specific member, as shown in Fig. 2, where multiple boxes represent individual learning.

According to Kim (1993, p. 11), the memory parts of the organisation that are relevant for organisational learning are those that constitute the active memory. In other words, "those that define what an organisation pays attention to, how it choose to act, and what it chooses to remember from its experiences-that are individual and shared mental models." Therefore, "organisational learning is dependent on individuals improving their mental models; making those mental models explicit is crucial to developing new shared mental models."

Like to individual learning, in organisational learning there is the weltanschauung beyond the routines. The weltanschauung of the organisation "determines how it interprets environmental responses, whether it will act on them, and what specific meaning it will employ if it chooses to act" (Kim 1993, p. 9). Individual frameworks become embedded in weltanschauung or the organisation's worldview. The vision of the organisation in relation to the world evolves slowly to encompass the current thinking of the individuals within it. Similarly, individual routines that have proven to be robust over time become a standard operating procedure. The strength of the link between individual mental models and shared mental models is a function of the amount of influence exerted by a particular individual or group of individuals

The model proposed by Kim $(1993,1998)$ also incorporates single-loop and doubleloop learning at the individual and organisational levels, as presented by Argyris and Shon (1996). Double-loop learning involves surfacing and challenging deep-rooted assumptions and norms of an organisation that have previously been inaccessible, either because they were unknown or known but not able to be discussed.

Individual double-loop learning (IDLL) is shown in Fig. 2 as the process by which each individual's learning affects individual mental models, which in turn affect future learning. Organisational double-loop learning (ODLL) occurs when individual mental models become incorporated into the organisation through shared mental models, which can then affect organisational action. In both cases, double-loop learning provides an opportunity for improving discontinuous steps where reshaping a problem can bring radically different potential solutions. The distinction between conceptual and operational learning and between weltanschauung and organisational routines are also integrated 
throughout the different stages. There is a box around the diagram to emphasize that the entire model is required to represent organisational learning.

Having explored the process of organisational learning and its relation to individual learning, the theory of transformative learning is introduced in the next section. This brings contributions to the model proposed by Kim (1993, 1998), which will be addressed in "Expanding the individual and organisational learning framework to include third order learning" section.

\section{Transformative learning}

Several authors suggest transformative learning as an alternative (e.g.: Sterling 20102011; Thomas 2009; Sipos et al. 2008; Moore 2005) when dealing with learning and sustainability. According to Sterling (2010-2011), in the current context, where there is a call for a re-examination of assumptions and values, critical thinking, and new creativity, the concept of transformative learning is surfacing.

However, in the evolution of transformative learning theory it was not initially linked to the great challenges of social change and sustainability. In fact, it emerged from the work of adult education by Mezirow (1978). It essentially refers to a qualitative change in the perception and construction of meaning by students in a specific learning experience in which the student asks or redrafts their assumptions or habits of thought.

According to Mezirow (1997), transformative learning

is the process of effecting change in a frame of reference. Adults have acquired a coherent body of experience (...) frames of reference that define their life world. Frames of reference are the structures of assumptions through which we understand our experiences. They selectively shape and delimit expectations, perceptions, cognition and feelings. They define our "line of action" (Mezirow 1997, p. 5).

Sterling (2010-2011) goes further and relates transformative learning to sustainability. In doing so, he introduces the idea of "levels of knowledge" to highlight that learning may involve and affect different levels of consciousness. Thus, we can learn at different levels of knowledge and meaning. Transformative learning is usually understood as learning that touches our deepest levels of knowledge and meaning, and, in doing so, then influences our most immediate and concrete levels of knowledge, perception and action.

Such learning is referred to by Bateson (1972) as third level learning. This author distinguished three kinds of learning and change (in addition to "zero learning"), which correspond to the increased learning capacity. These levels have been adopted by various learning and change theoretical scholars, particularly in the systemic learning domain and organisational change, such as Argyris and Shon (1996) - single, double and triple loop learning.

The three learning levels are summarised and represented in Table 1, with the arrow which represents a shift to the higher-order of learning. Sterling (2010-2011, p. 24) points out that, according to Bateson's and other theories derived from his model, learning levels are seen as nested systems with a superior learning order which affects the lower levels. "Thus, second order or meta-learning experience changes thinking and 
Table 1 Levels of learning

\begin{tabular}{|c|c|c|}
\hline Orders of change/learning & Seeks/leads to: & Can be labelled as: \\
\hline First order change/cognition & Effectiveness/efficiency & $\begin{array}{l}\text { "Doing things better" } \\
\text { Confirmative }\end{array}$ \\
\hline Second order change/meta-cognition & Examining and changing assumptions & $\begin{array}{l}\text { "Doing better things" } \\
\text { Reformative }\end{array}$ \\
\hline Third order change/epistemic learning & Paradigm change & $\begin{array}{l}\text { "Seeing things differently" } \\
\text { Transformative }\end{array}$ \\
\hline
\end{tabular}

Source: Sterling (2010-2011, p. 25)

actions in the first order domain, whilst epistemic learning causes changes in the second and first order domains."

The third level of learning, which can be called epistemic learning, involves a change in epistemology or operative ways of knowing and thinking that shape people's perceptions of the world and their interaction with it. This implies thinking and evaluating the fundamentals of thought itself. In other words, evaluating "the experience of seeing our worldview rather than seeing with our worldview so that we can be more open to and draw upon other views and possibilities" (Sterling 2010-2011, p. 23).

The argument for transformative learning is that, "learning within paradigm does not change the paradigm, whereas learning that facilitates a fundamental recognition of paradigm and enables paradigmatic reconstruction is by definition transformative". This level of learning (third order change) is consistent with a drastic shift of consciousness. Similarly, many critics see it as involving changing perceptions and arriving at an ethical and participatory transpersonal sensitivity. "In brief, an expansion of consciousness and a more relational or ecological way of seeing arises, inspiring different sets of values and practices" (Sterling 2010-2011, p. 23).

Since the sustainability beyond the status quo requires a transformation, which can be promoted by transformative learning, the next section presents a proposal to extend Kim's learning model for the insertion of the third level learning.

\section{Expanding the individual and organisational learning framework to include third order learning}

As discussed previously, transformation goes beyond double-loop learning to encompass third order learning. This refers to an expansion of individual frameworks, which happens through critical reflection. Thus, it is added the third order learning to the model proposed by $\operatorname{Kim}(1993,1998)$, represented as an extension of individual mental models (the blue rectangle in Fig. 3).

Similarly, this expansion is shown in Organisational Learning (the orange rectangle in Fig. 3). However, it is important to note that the mere expansion of individual mental models does not guarantee that the same action will happen in the organisation. In addition, this expansion occurs in different ways for different individuals in the organisation. Some members' mental models are magnified and others remain unchanged. Thus, the organisation needs to promote spaces where mental models of all internal members are shared. Moreover, spaces need to be opened for different stakeholders, enabling the 


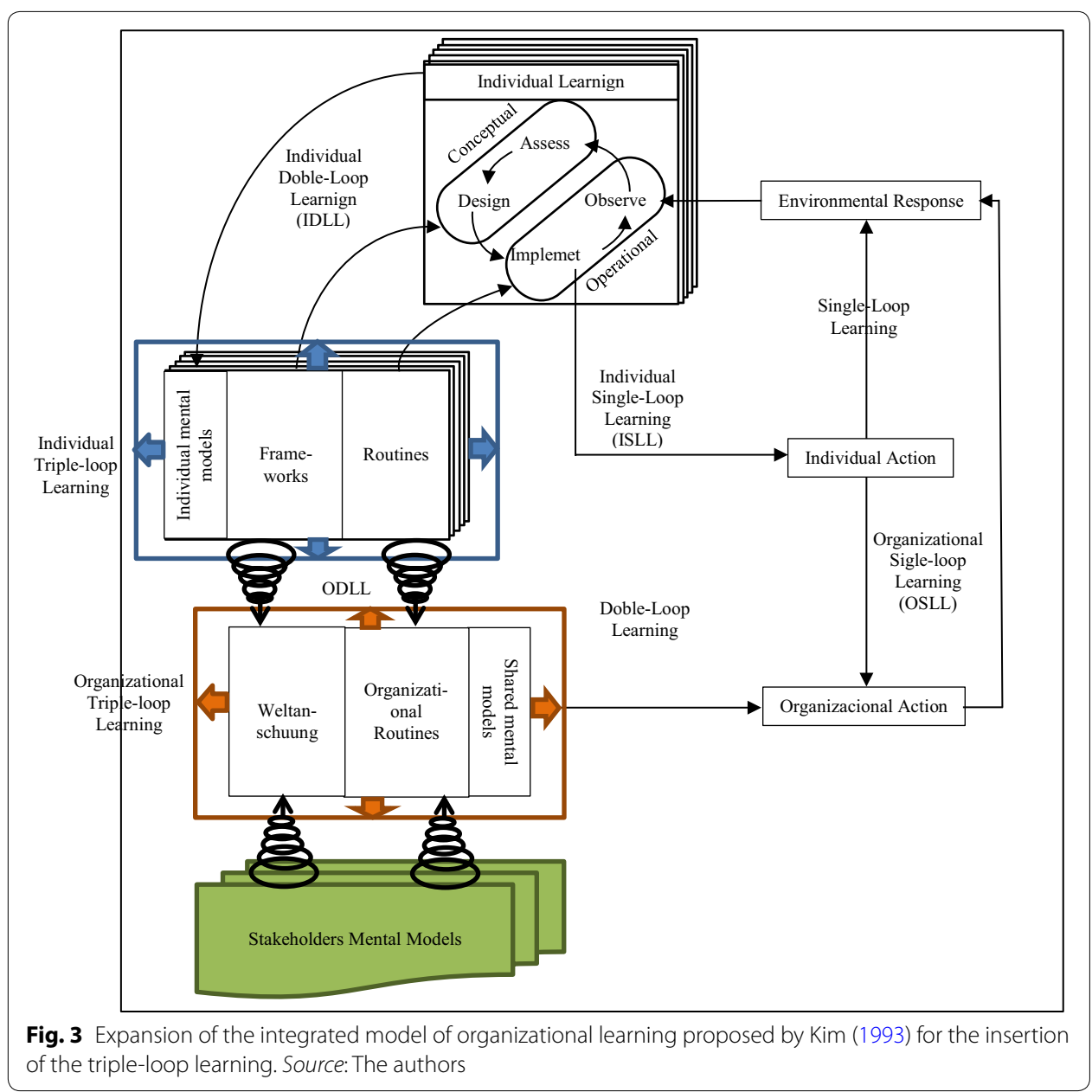

expansion of shared mental models. Thus, their interests will also be considered in decision-making, influencing in the actions of the organisation.

One way of achieving this is through the dialogic process and pluralism (e.g.: Waddell 2007; Floyd and Zubevich 2010; Wals and Schwarzin 2012). Wals and Schwarzin (2012) suggest that dialogic interaction is a key element for achieving a transition towards sustainability in people, organisations and society as a whole. They argue that dialogue or dialogic interaction is a concept that has been quite central in the fields of social and transformative learning for quite some time and it is central to increasing a new generation of members of society who act as stewards of the earth and its communities.

Regarding pluralism, Floyd and Zubevich (2010, p. 67) suggest that, "the more perspectives on an issue we can integrate, the better and more holistic our solution will be." However, they call attention to the fact that, "this is not simply a matter of giving every perspective equal voice. Rather, it is about critically reflecting on the relative merits (and shortcomings) of each perspective, and drawing out the partial truths of each". Thus, the dialogical process and pluralism also appear to be of fundamental importance in the proposal of this study. 
Another addition made to the model refers to the understanding of how the learning process occurs. Transformative learning works with the notion of building knowledge, rather than transference as proposed by $\operatorname{Kim}(1993,1998)$ in his model. In this sense, to represent such a construction that occurs in the transition to the third level of learning, the idea of a spiral was used instead of arrows. This was done in an effort to represent the construction or even the emergence of a new shared mental model, being that this model is more comprehensive and has transformative power.

\section{Methods}

In order to apply the proposed new framework, a case study was developed in the Economics for Transition program in an educational institution (called College $\mathrm{Z}$ here to preserve its identity) whose proposal is to promote "transformative learning for sustainable living". This case was chosen because the study aims to identify if, in fact, the proposed elements in the expansion of the model proposed by $\operatorname{Kim}(1993,1998)$ for the inclusion of the third level of learning were occurring in a program related to the management field of an institution which promotes the transformative learning.

The triangulation technique was used to collect data, using three sources of evidence: deep interviews, documentation and observation. Eight deep interviews were conducted with coordinators and professors of the program (both those internal to the College $\mathrm{Z}$ and those working for partner organisations), in February and March of 2014. All interviews were recorded and transcribed. Additionally, 12 relevant documents for research were surveyed. A third source of evidence was direct observation, during the visits made to the College Z in February and March of 2014. On-site observations, along with interviews and analysis of documents, made it possible to triangulate the data. Tables 2 and 3 show the subjects interviewed and documents analysed, respectively.

For data analysis, content analysis was used. In the next section, the main results are discussed.

\section{Results and discussion}

Initially, before discussing the main results and analysis, it is important to highlight some particularities of the educational institution studied and the program where the

Table 2 Performed interviews

\begin{tabular}{ll}
\hline Interview number & Interviewed \\
\hline 1 & Dean of College $Z$ \\
2 & $\begin{array}{l}\text { Professor at the College } Z \text { and co-responsible for the development of the Economics for } \\
\text { Transition Program. It is also the manager of Worldwide College } Z\end{array}$ \\
3 & Professor of the College Z and Coordinator of the Economics for Transition Program \\
4 & Professor at the Business School of the University Y and Professor of the Economics for \\
5 & Transition Program \\
6 & Co-founder of OPA and professor of the Economics for Transition Program \\
7 & Pirector of Finance and Business of OPB and professor of the Economics for Transition \\
& Professor of the University Y; Former student of the College Z and professor of the \\
\hline
\end{tabular}

Source: The authors 
Table 3 Analyzed documents

\begin{tabular}{ll}
\hline $\begin{array}{l}\text { Number of } \\
\text { the document }\end{array}$ & Description \\
\hline 1 & Program Specification of the Economics for Transition Program \\
2 & Program Approval document \\
3 & Student Handbook \\
4 & Institutional Website of College Z \\
5 & Institutional Website of University Y \\
6 & Quality Manual of College Z \\
7 & Institutional website of Organization Partner A (OPA) \\
8 & The Happy Planet Index: 2012 report-a global index of sustainable well-being- \\
9 & of OPA \\
10 & Institutional website of Organization Partner B (OPB) \\
11 & Strategic planning 2014/2017 of OPB \\
12 & Who we are and what we do-of OPA \\
\hline SOurce:The & Institutional Video of OPA \\
\hline
\end{tabular}

Source: The authors

study was conducted. Then an analysis of individual and organisational learning process is presented.

\section{College Z}

College $\mathrm{Z}$ was founded in 1991. It is located in a town with 7500 inhabitants, in Devon County, in southwest England. Its campus is located in a beautiful estate, surrounded by nature. Despite being a small college, it has excelled and is recognised worldwide due to its focus on environmental issues and differentiated teaching methods. It receives students from around the world. Currently, the institution offers programs from Short Term to Vocational Programs and Postgraduate studies.

The institutional values of College $\mathrm{Z}$ are (document 4):

- Community-living, working and learning together;

- Respect for all living systems-an ecological worldview

- Healthy body-healthy mind

Such values guide activities in the institution. Thus, all the programs are in groups of a maximum of 20 participants, focused on the interaction between students, professors and facilitators of the program. Various teaching methods are employed to ensure both, groups and individuals, learning opportunities and "a real sense of co-creation and belonging" (document 4).

The key elements of College Z's holistic educational approach can be summarised (documents 1, 3, 5 and 6):

- Community living and working within the residential setting of Z College;

- Acknowledging and developing the whole person-intellectual, emotional, ethical and practical;

- Valuing transdisciplinary approaches and different ways of knowing (analytical, sensory perception, feelings and emotions, and intuitive); 
- Emphasis on embodiment and practical action in participants own lives;

- Engaging with a range of teaching and learning methods from lectures and seminars to participatory and experiential learning methods as well as reflective inquiry;

- Developing a blended learning approach, which complements Z College's approach to transformational learning through living and working together, with online learning and networking;

- Attracting participants, teachers and practitioners from all over the world.

The organisation now has a small team of about 20 people, among staff and professors, many of them working on a part-time basis, as well as visiting professors, collaborators and facilitators. Some of the staff and the professors live on campus (document 4).

Additionally, it is important to note that during the courses, most students live on campus and are involved in daily activities. The proposal that students live in community, participating in the daily activities and providing services to each other is essential in the College Z's teaching-learning process. As stated by one of the program professors, "living in community is, at least fifty percent, or even one hundred percent of the learning here" (Interviewee 2).

\section{The economics for transition program}

The postgraduate program in "Economics for Transition" is about "creating an economic system fit for the ecological, social, economic and ethical challenges of the 21st century as we make the great transition to low carbon, high well-being and resilient economies" (document 1).

The program was created for the purpose of being an alternative proposal to the mainstream. Thus, since its creation it has had a different view of economics and its relationship to society and the environment.

The main objectives of the program include (documents 1 and 5):

- To develop students' knowledge and reflective understanding of transition pathways to low carbon, high well-being and resilient economies;

- To acknowledge and develop the whole person as a participant in co-creating these transition pathways;

To develop and enhance the individual's cognitive/intellectual skills; key transferable skills; and practical skills for sustainable living, working and ecological citizenship.

The challenges facing society that the program will address include (document 1 ):

- the triple crunch of climate change, financial crises and peak oil;

- the crises in ecosystem health and social well-being across the globe;

- the inter-connected nature of these crises and how they are systemically linked with the global economic model;

- the significant opportunities for transformational and sustainable change that these multiple crises provide. 
The Program Specification highlights the distinctive features of the program. The most important are: new paradigm thinking and practice, unique holistic educational model, collaborative approach, and flexible learning (document 1 ).

The new paradigm refers to a "radical economic model (...) that has inspired a whole generation of thinkers and practitioners in new approaches to economics to address the inter-related sustainability challenges of our times" (document 1). The program is also "inspired by the well-established and successful MSc in Holistic Science by offering new paradigm thinking and practice in economics based on contemporary scientific understanding of systems ecology and complexity theory applied to the socio-economic domain" (document 1 ).

It is important to emphasize that the postgraduate degree in Economics for Transition was developed in partnership with three other organisations:

- University Y: Is also located in southwest England. It is the main institution which provides thee postgraduate diploma for College Z's programs and also provides professors. With over 26,900 students, it is the 15th largest university in the UK in total number of students. It also has nearly 2900 employees making it one of the largest employers in the southwest of England (HESA 2014).

- The Organisation Partner A (OPA): Seeks to inspire, encourage, connect, support and train communities as they self-organise around the transition model, creating initiatives that rebuild resilience and reduce $\mathrm{CO}_{2}$ emissions. It works by creating a healthy human culture that meets the human needs of a community, means of subsistence and fun (document 9).

- Organisation Partner B (OPB): Is a think tank in the United Kingdom, which seeks to promote social, economic and environmental justice. It aims to "produce a great transition-to transform the economy so that it works for people and the planet." Its mission is to "relaunch the change to a new economy through big ideas and a new vision" (document 7).

\section{Third order individual and organisational learning}

With regard to the Individual and Organisational Learning Framework for the inclusion of the proposed third order learning (Fig. 3), the main results are described below. At the individual level, it was observed from the case study that individuals who are now part of College $\mathrm{Z}$ went through a magnifying process of their reference frames.

Results show that most of the directors/coordinators and professors that are now part of the organisation went through a learning process to the third level before becoming employees of the College Z. Therefore, given the difficulty of changing the deep organisational structure and in view of the incompatibility of how these individuals came to understand the issue of sustainability and how this issue is addressed by the programs related to the field of management in general-that are mainstream-they looked for an organisation that was more compatible with their beliefs. Thus, by passing through the transformative learning process, these individuals migrated to an organisation whose values, since its formation, are related to the transformation to sustainability-College $\mathrm{Z}$.

Most of these individuals studied at traditional schools within the mainstream, where they had their first experiences in the market. However, over the years based on their 
experiences and studies, they changed their view about the world-expanding their vision in relation to individuals, organisations and sustainability. The words of two professors of the program highlight this process:

My background is actually in mainstream economics and I've worked all my life in economics and spent some time in international development where I had kind of the insight, or realisation that the economic development we were pursuing was not creating desirable solutions, and that, in fact, that was a huge wealth in many of the countries that I worked, which wasn't recognised, which was the kind of the health and wealth of community and the connection to place and the spirit of the people, so I thought we had to look at transforming our economic model here, back in the west. So, I've worked in different forms (Interviewee 2).

Well, I became aware and concerned about environmental issues fifteen years ago (...) I was working in a bank that the current financial economic system, if you like, is clearly incompatible with environmental protection or, you know, preventing environmental harm and, so I became interested in it. And I did it for the Master's degree in the balances of economics on the environmental policy in the economics (...) So I just, you know, got more interested in it (Interviewee 6).

For a few individuals, part of this process occurred within College Z, such as the cocreator of the program. But for the majority, this change took place due to their experiences in other organisations, including traditional universities, such as the director of College Z. Being on the third level of learning, they migrated to an organisation with College Z's characteristics so they could develop their work. Thus, it was observed from the data collected that there was in fact an extension of frameworks of individuals who are now part of the College $\mathrm{Z}$.

With regard to the organisational level, the results show that there are promoting spaces in which the mental models of all the internal members are shared, along with different stakeholders, allowing for the amplification of shared mental models. It is important to remember that the Economics for Transition program as already noted, was developed in partnership with stakeholders (University Y, OPA and OPB).

One of the interviewee's comments on the creation process reflect this:

Some colleagues at [ $Z$ College] had the idea, the time was right to develop a Master's degree, in what we might loosely call a sort of an alternative to mainstream (...) And so, what they did, was they thought about, they knew the university would have to be involved because they didn't have degree ordering power, so the university will need it, because we could order degree. So they approached us, they also approached the [OPB] in London (...) they're basically a NGO who's interested in alternatives to mainstream economics. (...) And then the [OPA]. (...) Z College then basically invited us to a workshop and we basically engaged in a brainstorming exercise, thinking about what we wanted to achieve, how we could achieve it, what the loose terms for the course content would be (Interviewee 4).

In addition to participating in the program creation process, these partners have also worked in the teaching-learning process, contributing in different ways. As previously mentioned, professors from University Y mainly contribute to academic knowledge, 
providing support in relation to research methodology and supervision of dissertations. Professionals from the other two organisation partners (OPA and OPB) help primarily with practical knowledge, bringing examples and experience in transition projects and in relation to the new economy, respectively. The following excerpts illustrate this:

[Y University] leads on and provides support and supervision for the dissertation that forms part of the Economics for Transition Master's programme. This includes guidance on choosing and planning your dissertation; workshops on research methods related to the dissertation; and identifying suitable supervisors from the [Y] Graduate School of Management and other departments at the University, as appropriate (document 4).

Pioneers from [OPA] regularly visit the College and have taught in short courses and the postgraduate programmes. As the Transition movement has spread throughout the UK, Europe and far beyond, the OPA has emerged as a growing social movement supporting communities worldwide to develop and implement action plans towards becoming low carbon and resilient communities, organisations and businesses (document 4).

$[O P B]$ combines rigorous analysis and policy debate with practical solutions on the ground towards increased wellbeing and environmental sustainability. It works with all sections of society in the UK and internationally to create more understanding of the new economics and to develop strategies for desirable change. (...) Core staff and fellows of $[\mathrm{OPB}]$ have been involved with co-designing the programme and will provide a number of the key teachers (document 4).

Another important aspect observed in the study was that the College was designed to be a learning community. Thus, all members participating in the college are involved in this learning community and have a responsibility in relation to their learning experience and that of others. According to College Z's Quality Manual, "the boundaries of this experience are not restricted to the subject matter of their particular focus of study and extend to a shared responsibility for the learning and living environment". It adds that, for this, College Z strives to "provide different spaces, styles and opportunities for learning. This diversity extends to creating different ways of interacting with other community members and in being of service to the community, the planet and ourselves" (document 6).

The Quality Manual clearly states that the learning community is central to College Z:

The practice of a learning community remains at the heart of the learning experience at [ $Z$ College]. This commitment to community has a number of manifestations. These include, but are not limited to, the acknowledgement that everyone at the College be they students on any programme or course, volunteers, staff (either faculty or non-faculty), visiting teachers or facilitators, all have a significant contribution to make to their own and one another's learning experience (document 6).

This is one of the distinct aspects of College Z. A professor from University Y highlights this difference, arguing that it provides a unique and complete experience for the students: "The other important thing is (...) that the students reside there, they share the cooking, the cleaning, that's kind of thing, so it is very much a whole experience" 
(Interviewee 4). He adds that "this is a major feature of the College Z programs", highlighting the fact that, without it, "they could not reach the same things that they reach up there" (Interviewee 4).

In this sense, the involvement of different actors is part of College Z's strategy and teaching-learning process. As stated in some documents, it "attracts participants, teachers and practitioners from all over the world and this international flavour has always been an important element of the [Z College] experience" (documents 1 and 3).

The diversity of actors and perspectives is highlighted in various documents and excerpts from interviews, as illustrated in the following example:

[Z College] attracts people from all walks of life from across the globe-from business leaders and entrepreneurs to policy makers and social and environmental activists. (...) It provides a unique opportunity to study with leading thinkers and academics, activists and practitioners in the new economy from a range of different perspectives (document 1).

The main actors involved in the College Z's learning community are: students from different programs (both short programs as other postgraduate programs developed at College Z); employees; internal and external professors (visiting faculty); volunteers; alumni and a network of partners (local and international).

\section{Conclusions}

This article aimed to present a proposal to expand the integrated model of organisational learning proposed by $\operatorname{Kim}(1993,1998)$, for the insertion of transformative learning in programs related to management. It also sought to present the results of a case study for the application of this framework in a program related to the management area.

Thus, a new framework was proposed expanding the integrated model of organisational learning for the insertion of transformative learning. The main contributions of the model are to highlight of the need to expand individual frameworks, which happens through critical reflection, in order to achieve transformative learning. Similarly, at the organisational level, the expansion of shared mental models and organisational learning of third level needs to promote spaces where mental models of all internal members are shared and open spaces for participation of different stakeholders. Dialogical process and pluralism help this process and were identified in the case study.

These aspects were observed in the case study, showing that it is possible to promote transformative learning in programs related to the management area. However, in order to do so, there must be both the willingness and openness of the people and the organisation, so they can go through a transformative learning process. Therefore, if business schools aim to promote transformation, they must become organisations that foster learning beyond the first level, making room for the paradigm shift and the emergence of new ways for society. For this, as learning organisations, they need to go through a process of third order learning (epistemic learning), changing themselves, to promote individual transformative learning, profound changes in other organisations and to be agents of change in society. 
Authors' contribution

LCP and EAP carried out the literature review, general paper conceptualizations and theoretical framework. LCP carried out the data collection and the analysis and also drafted the manuscript. Both authors read and approved the final manuscript.

\section{Author details}

${ }^{1}$ IFRS (Federal Institute of Education, Science and Technology of Rio Grande do Sul), Canoas, Rio Grande do Sul, Brazil.

${ }^{2}$ UFRGS (Federal University of Rio Grande do Sul), Porto Alegre, Brazil.

Acknowledgements

The authors thank the CAPES Foundation for the financial support which enabled data collection.

\section{Competing interests}

The authors declare that they have no competing interests.

Received: 5 November 2015 Accepted: 25 February 2016

Published online: 17 March 2016

\section{References}

Argyris C (1964) Integrating the individual and the organization. Wiley, New York

Argyris C, Shon D (1996) Organizational learning II: theory, method and practice. Addison-Wesley, Reading

Barbieri JC (2007) Gestão ambiental empresarial: conceitos, modelos e instrumentos. Saraiva, São Paulo

Barin-Cruz L, Pedrozo E, Estivalete VFB (2006) Towards sustainable development strategies: a complex view following the contribution of Edgar Morin. Manag Decis 44(7):871-891

Bateson G (1972) Steps to an ecology of mind. Chandler, San Francisco

Batie S (2008) Wicked problems and applied. Am J Agric Econ 90(5):1176-1191

Carvalho SLG, Brunstein J, Godoy AS (2014) Um panorama das discussões sobre educação para a sustentabilidade no ensino superior e nos cursos de Administração. In: Brunstein J, Godoy AS, Silva HC (eds) Educação para Sustentabilidade nas escolas de Administração. RiMa Editora, São Paulo, pp 201-228

Demajorovic J, Silva HCO (2012) Formação Interdisciplinar e Sustentabilidade em Cursos de Administração: Desafios e Perspectivas. Rev Adm Mackenzie (RAM) 13(5):39-64

Dias R (2006) Gestão Ambiental: responsabilidade social e sustentabilidade. Atlas, São Paulo

Floyd J, Zubevich K (2010) Linking foresight and sustainability: an integral approach. Futures 42:59-68

Gladwin TN, Kennelly JJ, Krause TS (1995) Shifting paradigms for sustainable development: implications for management theory and research. Acad Manag Rev 20(4):874-907

Graaf HJ, Musters CJM, Leurs WJ (1996) Sustainable development: looking for new strategies. Ecol Econ 16:205-216

HESA — Higher Education Statistics Agency (2014) https://www.hesa.ac.uk/. Accessed 21 Mar 2014

Hopwood B, Mellor M, O'brien G (2005) Sustainable development: mapping different approaches. Sustain Dev 13(1):38-52

Kim DH (1993) The link between individual and organizational learning. Sloan Management Review, Cambridge, pp $37-50$

Kim DH (1998) O Elo entre a Aprendizagem Individual e a Aprendizagem Organizacional. In: Klein DA (ed) A gestão estratégica do capital intelectual. Qualitymark, Rio de Janeiro

Leal-Filho W (2000) Dealing with misconceptions on the concept of sustainability. Int J Sustain High Educ 1(1):9-19

March JG, Olsen JP (1975) The uncertainty of the past: organisational learning under ambiguity. In: March JG (ed) Decision and organisations. Blackwell, Oxford

Mezirow J (1978) Perspective transformation. Adult Educ 28(2):100-110

Mezirow J (1997) Transformative learning: theory to practice. New Dir Adult Contin Educ 74:1-12

Moore J (2005) Is higher education ready for transformative learning? A question explored in the study of sustainability. J Transform Educ 3(1):76-91

Palma LC, Oliveira LM, Viacava KR (2011) Sustainability in Brazilian Federal Universities. Int J Sustain High Educ 12(3):250-258

Prange C (2001) Aprendizagem organizacional: desesperadamente em busca de teorias? In: Easterby-Smith M et al (eds) Aprendizagem Organizacional e Organização de Aprendizagem. Atlas, São Paulo

Senge PM (1990) A quinta disciplina. Editora Best Seller, São Paulo

Sipos Y, Battisti B, Grimm K (2008) Achieving transformative sustainability learning: engaging head, hands and heart. Int J Sustain High Educ 9(1):68-86

Sterling S (2010-2011) Transformative learning and sustainability: sketching the conceptual ground. Learn Teach High Educ 5:17-32

Steurer R, Langer ME, Konrad A, Martinuzzi A (2005) Corporations, stakeholders and sustainable development I: a theoretical exploration of business-society relations. J Bus Ethics 61(3):263-281

Stubbs W, Cocklin C (2008) Teaching sustainability to business students: shifting mindsets. Int J Sustain High Educ 9(3):206-221

Thomas I (2009) Critical thinking, transformative learning, sustainable education, and problem-based learning in universities. J Transform Educ 7(3):245-264

Veiga JE (2005) Desenvolvimento sustentável_desafio do século XXI. Garamond, Rio de Janeiro

Waddell S (2007) Realising global change: developing the tools; building the infrastructure. J Corp Citizensh 26:69-84

Wals AEJ, Schwarzin L (2012) Fostering organizational sustainability through dialogic interaction. Learn Organ 19(1):11-27 